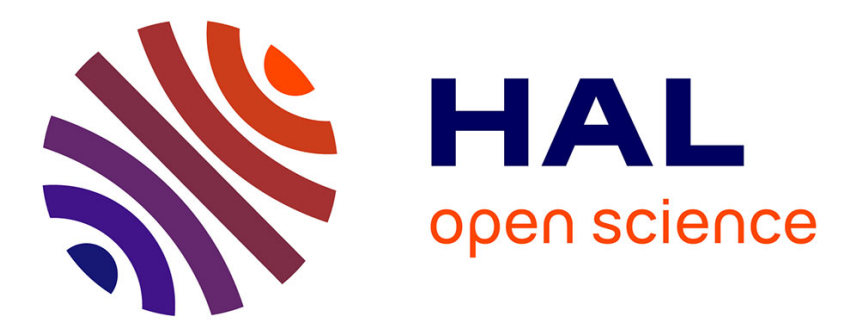

\title{
Comparative ultrastructure of the spermatogenesis of three species of Poecilosclerida (Porifera, Demospongiae).
}

Vivian Vasconcellos, Philippe V Willenz, Alexander Ereskovsky, Emilio Lanna

\section{- To cite this version:}

Vivian Vasconcellos, Philippe V Willenz, Alexander Ereskovsky, Emilio Lanna. Comparative ultrastructure of the spermatogenesis of three species of Poecilosclerida (Porifera, Demospongiae).. Zoomorphology, 2019, 138 (1), pp.1-12. 10.1007/s00435-018-0429-4 . hal-02012263

\section{HAL Id: hal-02012263 \\ https://hal-amu.archives-ouvertes.fr/hal-02012263}

Submitted on 10 Dec 2019

HAL is a multi-disciplinary open access archive for the deposit and dissemination of scientific research documents, whether they are published or not. The documents may come from teaching and research institutions in France or abroad, or from public or private research centers.
L'archive ouverte pluridisciplinaire HAL, est destinée au dépôt et à la diffusion de documents scientifiques de niveau recherche, publiés ou non, émanant des établissements d'enseignement et de recherche français ou étrangers, des laboratoires publics ou privés. 
1 Comparative ultrastructure of the spermatogenesis ofthree species of Poecilosclerida (Porifera,

2 Demospongiae)

3 Vivian Vasconcellos ${ }^{1,2}$, Philippe Willenz ${ }^{3,4}$, Alexander Ereskovsky ${ }^{5,6}$ and Emilio Lanna ${ }^{1,2 *}$

$4{ }^{1}$ Universidade Federal da Bahia, Instituto de Biologia, Rua Barão de Jeremoabo, s/n, Ondina, 5 Salvador, BA, 40170-115, Brazil.

$6 \quad{ }^{2}$ National Institute of Science and Technology in Interdisciplinary and Transdisciplinary

$7 \quad$ Studies in Ecology and Evolution (INCT IN-TREE)

$8 \quad{ }^{3}$ Royal Belgian Institute of Natural Sciences, Taxonomy and Phylogeny, 29 Rue Vautier, B

91000 Bruxelles, Belgium

$10{ }^{4}$ Université Libre de Bruxelles, Laboratoire de Biologie Marine, Avenue F.D. Roosevelt 50, B 111000 Bruxelles, Belgium

$12{ }^{5}$ Mediterranean Institute of Biodiversity and Ecology (IMBE), Aix Marseille Université, CNRS, 13 IRD, Avignon Université, Station Marine d'Endoume, Rue de la Batterie des Lions, F 13007,

14 Marseille, France

$15{ }^{6}$ Dept. Embryology, Faculty of Biology, Saint-Petersburg State University,

16 Universitetskayaemb.7/9, RU 199034, Saint-Petersburg, Russia.

17 *Correspondenceauthor: emiliolanna@gmail.com

19 ORCID Vivian

20 ORCID Philippe

21 ORCID Alexander 0000-0003-1079-7204

22 ORCID Emilio: 0000-0002-6170-1842

23 Telephone number of the correspondence author +5571 3283-6567

24 Abstract. 
The spermatogenesis of Porifera is still relatively poorly understood. In the past, it was accepted that all species presented a primitive-type spermatozoon, lacking special structures and acrosome. Nonetheless, a very peculiar spermatogenesis resulting in V-shaped spermatozoonwith acrosome was found in Poecilosclerida, calling into question the reproductive and evolutionary aspects of Porifera.We investigated theultrastructure of the spermatogenesis of three different species of Poecilosclerida (Porifera, Demospongiae):Iophon proximum, I. piceus and Tedania ignis. In all three species,spermatogenesis wassynchronizedwithin the spermatic cysts. Iophon proximumand $T$. ignispresented elongated sperm cells, but in I. piceus their shape was globular, suggesting a primitive spermatozoon. A structure resembling an acrosome was only found in T.ignis. Apparently, the type of spermatozoid in poeciloscleridsis not dictated by the phylogeny nor the environment. Nonetheless, we are proposing that the modified type of spermatozoon is the ancestral state in Poecilosclerida.

Key-words: Reproduction, Sponges, Gametogenesis,Modified Spermatozoa; Acrosome

Introduction

Spermatogenesis is the process that gives rise to the male (usually motile) gamete of animals, i.e. the spermatozoon. In general, this process is characterized by the establishment of the germ-line, successively followed by a proliferation of germ cells, production of spermatids by meiosis and finally the differentiation of the mature spermatozoa (L'Hernault 2006; WhiteCooper et al. 2009). Spermatozoa are among the most specialized of all metazoan cells. Their diverse and sometimes intricate morphologies are adapted to a primary function - the transmission of their own genetic contents to an egg of the same species (White-Cooper et al. 2009).

Sponges (Porifera) lack special organs or systems (Bergquist 1978; Simpson 1984) and their spermatogenesis occurs through the transdifferentiation of somatic cells into germ cells usually in non specific regions of the animal body (Boury-Esnault and Jamieson 1999; Ereskovsky 2010). In Porifera, spermatocytes can either derive from archaeocytes or from choanocytes, but in most Demospongiae, spermatocytes are usually derived from choanocytes (Maldonado and Riesgo 2008; Ereskovsky 2010). In this class, choanocytes will form aggregates progressively bordered by a follicular layer of pinacocyte-like cells, forming the socalled spermatic cysts (Reiswig 1983; Boury-Esnault and Jamieson 1999). Spermatogenesis in sponges may either occur synchronously in all spermatic cysts of a given specimen, or in a given population, or only within individual spermatic cysts, independently from each 
other(Reiswig 1983). In general, as in other animals, sponges also present four spermatogenicstages:the first stagebegins with spermatogonia, which suffer two consecutive divisions resulting in primary spermatocytes and secondary spermatocytes, when the cells remain interconnected by cytoplasmic bridges. During the third stage, these cells differentiate into haploid spermatids.At the fourth stage, spermatozoa become mature(Riesgo and Maldonado 2009; Ereskovsky 2010; Lanna and Klautau 2010).

Invertebrate spermatozoa can be divided into three types: (i) primitive, (ii) modified, and (iii) aberrant, the first two types being the most common ones (Hodgson 1986; Reunov 2005). The main difference among these types are the position/presence of different compartments of the cell, including acrosome, and the shape of the sperm.Although it has long been assumed that Porifera presenteda primitive type of spermatozoa, today a great diversity in their morphology and size is indubitable.Reiswig (1983) described at least eleven different shapes of sperm cells in Porifera.In most species of Poecilosclerida (Demospongiae) investigated so far, mature spermatozoa are elongated cells (Ereskovsky 2010). However, adifferentform of spermatozoa wasrecently described for this lineage: a sophisticated V-shaped form in Crambe crambe(Schmidt, 1862)(Riesgoand Maldonado 2009).

The order Poeciloscerida is one of the most speciose in the phylum Porifera, comprising four suborders, 25 families, 142 genera and more than 2500 species (van Soest et al. 2018). However, neither the order, nor many of the inner clades are monophyletic (Redmond et al. 2013). As occurs in many other lineages of sponges, phylogenies based on molecular markers provides groups that have no morphological characteristics to support them, probably related to the homoplasy of the main characters used in the taxonomy of Porifera (Redmond et al. 2013). This lack of congruence between molecules and morphology are not an exclusivity of the sponges, but in other groups of metazoans, the use of the ultrastructure of the sperm cells in the phylogenies has helped to better understand the relationship among the clades (reviewed in Tudge 2009).

Apart from showing different types of spermatozoa, there is no pattern for the origin of germ line in Poecilosclerida. In Mycale fistulifera (Row, 1911) and in the carnivorous sponge Lycopodinaoccidentalis(Lambe, 1893) spermatocytes were suggested to originate from archaeocytes (Meroz and Ilan 1995; Riesgo et al. 2007).On the other hand, in Hemimycalecolumella(Bowerbank, 1874) and Crellaelegans (Schmidt, 1862)spermatocytes seem to originate from choanocytes (Pérez-Porro et al. 2012).In addition, it has been postulated that the shape of the spermatozoon is influenced not only by the phylogenetic position of the species, but also by the physiological and functional demands during dispersal of the gamete and its subsequent fertilization process (Franzén 1956; Pitnick et al. 2009). In sponges, both the 
functional and phylogenetic significance of the diverse morphologies remain poorly understood. Expanding the number of species from different lineages of Poecilosclerida will help to understand the evolution of the group and also the usefulness of the ultrastructure of sperm cells to comprehend the phylogenetic relationship within this lineage of sponges. Therefore, in the present study, we compared the ultrastructure of the spermatogenesis of three species distantly related within the Poecilosclerida phylogeny (Vargas et al. 2015):Tedania ignis(Duchassaing \& Michelotti, 1864) (Fig. 1a), Iophon proximum(Ridley, 1881)(Fig. 1b), and Iophon piceus(Vosmaer, 1881) (Fig. 1c), found in the tropical, temperate and polar zones of the world, respectively.

Material and Methods

Tissue samples of Tedaniaignis (with ca. $5 \mathrm{~cm}^{3}$ ) were collected at Porto da Barra,

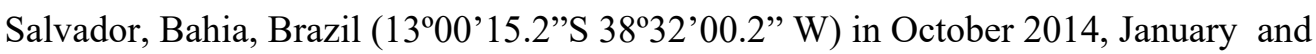
November 2015, at 1-2 m depth. Specimens ofIophonproximumwere collected in Comau Fjord, Southern Chilean Patagonia (42 $24^{\prime} 9.66^{\prime}$ 'S - 72²5'14.01'W) in April 2004, at 20-25 m depth. Five specimens of Iophon piceuswere collected near the White Sea Marine Biological Station «Belomorskaia» of St. Petersburg State University (Kandalaksha Bay, White Sea) (66 $16^{\circ}$ N , $33^{\circ} 39^{\prime} \mathrm{E}$ ), at $16 \mathrm{~m}$ depth in July 2002 . While T.ignis was collected by snorkeling, both species of Iophonweresampled bySCUBA diving.

Specimens of $T$. igniswere processed for both light and electron microscopy. For light microscopy (LM), specimens were fixed in a solution of saline formaline (4\%) for $24 \mathrm{~h}$ and processed for standard histology, as described in Lanna et al. (2018). For transmissionelectron microscopy (TEM), fragments were fixed (for at least $24 \mathrm{~h}$ at $4{ }^{\circ} \mathrm{C}$ ) in a solution of $25 \%$ glutaraldehyde, $0.2 \mathrm{M}$ of sodium cacodylate $(\mathrm{pH} 7.0)$ and filtered seawater (1:4:5) or fixed in a solution of $25 \%$ glutaraldehyde, $0.4 \mathrm{M}$ PBS and $0.34 \mathrm{M} \mathrm{NaCl}$ (1:4:5).For scanning electron microscopy (SEM), fixed fragments were further rinsed with filtered seawater, dehydrated through a graded ethanol series, fractured in liquid nitrogen, thawed in $100 \%$ ethanol at ambient temperature and dried by the critical point method from carbon dioxide before being mounted onaluminum stubs, coated with gold using a sputter coater and observed with a JEOL (JSM$6390 \mathrm{LV}$ )scanning electron microscope at $12 \mathrm{kV}$. For transmission electron microscopy (TEM), fixed fragments were rinsed three times in $0.2 \mathrm{M}$ sodium cacodylate buffer and post-fixed in a solution of $1 \%$ osmium tetroxide for 30 minutes at room temperature. Later, specimens were dehydrated in a graded acetone series and embedded in Epon. Semi-thin sections ( $1 \mu \mathrm{m}$ thick) were stained with toluidine blue.Ultrathin sections (60-90 nm thick) double-stained with uranyl 
acetate and lead citrate (Reynolds 1963)were observed with a JEOL (JEM-1230) transmission electron microscope.

Specimens of both species ofIophon were also fixed for light and electron microscopy, but using different protocols. Iophonpiceus specimens prepared for light microscopy were immersed in a Bouin fixative. Vouchers were then dehydrated through an ethanol series, immersed in a celloidin-castor oil mixture and then in chloroform before embedding in paraffin. Thick sections ( $6 \mu \mathrm{m}$ thick) were mounted on glass slides and stained with Mayer's hematoxylin, and eosin.For electron microscopy, fragments of about $1 \mathrm{~mm}^{3}$ were fixed in $2.5 \%$ glutaraldehyde in phosphate buffer $(\mathrm{pH} 7.4)$ at room temperature for $1 \mathrm{~h}$. After fixation, fragments were washed in phosphate buffer and postfixed in 1\% osmium tetroxide in phosphate buffer for $1 \mathrm{~h}$. Samples were dehydrated through a graded ethanol series and embedded in EponAraldite.

Vouchers of Iophon proximum(specimen RBINS-IG 32231-POR $8209=$ MNRJ 8209) were fixed when arriving at the surface in $4 \%$ glutaraldehyde in $0.2 \mathrm{M}$ sodium cacodylate buffer(pH 7.4) supplemented with $0.35 \mathrm{M}$ sucrose and $0.1 \mathrm{M} \mathrm{NaC} 1$ to obtain a final osmotic pressure of $1105 \mathrm{mOsM}$ for $24 \mathrm{~h}$ at $4^{\circ} \mathrm{C}$. Vouchers were then washed six times for $10 \mathrm{~min}$ in 0.2 $\mathrm{M}$ sodium cacodylate buffer ( $\mathrm{pH} 7.4$ ) and post fixed for $1 \mathrm{~h}$ in $1 \%$ osmium tetroxide in $0.2 \mathrm{M}$ sodium cacodylate and $0.3 \mathrm{M} \mathrm{NaCl}$, dehydrated through a graded ethanol series and embedded in ERL 4206 according to Spurr (1969).

For both Iophon species, sections were obtained with a diamond knife on a Leica Ultracut UCT ultramicrotome. Semi-thin sections ( $1 \mu \mathrm{m}$ thick) were dried onto slides and stained with methylene blue-borax. For TEM, thin sections double-stained with uranyl acetate and lead citrate (Reynolds 1963) and later observed with a Tecnai 10 transmission electron microscope. For SEM, specimens were fractured in liquid nitrogen, critical-point-dried, sputter coated with gold-palladium, and observed with a Philips (XL30 ESEM)scanning electron microscope.

\section{Institutional abbreviations and acronyms}

MNRJ = Museu Nacional da Universidade Federal do Rio de Janeiro, Brazil; RBINS = Royal Belgian Institute of Natural Sciences

\section{Results}

Tedania ignis

Tedania ignis is a simultaneous hermaphrodite and its spermatogenesis occurs all year round (Lanna et al. 2018). Spermatic cysts were enveloped by a single layer of follicle cells 
(Fig.2a-b), were rounded, and measured ca. $45 \mu \mathrm{m}$ in diameter(Fig.2b). They were spread in the choanosome without any clear pattern of distribution. Different stages of maturation occurred in the same individual, without synchronism between cysts, but the spermatic cells matured at the same time within each cyst. Somatic cells were seldom observedinside the spermatic cysts (Fig.2c).

The first stage of spermatogenesis was characterized by the presence of large cells (3.6 $\mu \mathrm{m}$ in diameter) with spherical shape, hyaline cytoplasm and a large nucleus $(2.1 \mu \mathrm{m}$ in diameter). In this stage, the nucleus was rounded and its ratio to the cytoplasm was low. The chromatin was partially condensed and spread evenly in the nucleus (Fig. 2d). The cytoplasm presented a relatively well-developed Golgi apparatus and some spherical mitochondria (Fig. 2e).

The second stage of the spermatogenesiscomprised cells showinga volume reduction ( $2.2 \mu \mathrm{m}$ in diameter) due to the division of the spermatogonia (Fig. 3a), which apparentlyunderwent successive divisions toward primary and latersecondary spermatocytes. Primary spermatocytes were rounded, with a hyaline cytoplasm filled with small clear vesicles, a prominent Golgi apparatus and a rounded nucleus. The most important characteristic inthis stage was the presence of synaptonemal complexes next to the nuclear envelope (Fig. 3b). In the next stage (secondary spermatocyte), another roundof cell divisions occurred, but cytoplasmic bridges kept the daughter cells connected. These cells were smaller $(<2.0 \mu \mathrm{m})$ than in the previous stages, the nucleus ratio to the cytoplasm was ca. 1:1, and the cytoplasm presented several small mitochondria. In this stage, the rounded nucleus started to condense, as some heterochormatin spots were observed in different areas (Fig. 3d). Following the second division, the secondary spermatocytes started to differentiateinto spermatids, still connected through cytoplasmic bridges (Fig. 3c, f).However,dramatic changes occurred during this stage. The volume of the cytoplasm started to decrease, probably by shedding clear vesicles into the lumen of the spermatic cyst. Meanwhile, a flagellum started to emerge close to the nucleus, which was still rounded (Fig. 3e). Later, while the condensation of chromatin progressed, the nucleus became elongatedandan axoneme as well as some mitochondria were observednext to its basal region (Fig. 3f). In this early stage, the spermatid could present a curved shape (Fig. 3c, f, h), but when itfurther differentiated to become a sperm cell, the cytoplasm shedding induced the elongation of the cell, withmitochondria still rounded and gathered in the posterior part of the cell body, next to the flagellum insertion (Fig. $3 \mathrm{~g}$ ). In the late spermatid stage, the nucleus was elongated, occupyingmost of the cytosol and an electron dense material,likely pre-acrosomal vesicles, was present at the tip of the cell (between the plasma membrane and the apical portion of the nucleus), resembling a pre-acrosomal complex (Fig. 3i). No fully mature spermatozoon could be observed in electron microscopy despite the timing of the samples collections. 
In April 2004, the investigated specimens ofIophon proximumwhere actively carrying out their spermatogenesis. As in T. ignis(and most Demospongiae), spermatogenesis in $I$. proximum took place in spermatic cysts. The shape of spermatic cysts were rounded, they measured from 6 to $11 \mu$ mand it was covered by follicle cells. Spermatic cysts were located in the choanosome of the sponges without any special localization (Fig. 4a). The follicle cells were flattened (Fig. 4b), with a lentil-like shape next to the nuclear region. The outward and inward surfaces of the follicle cells had numerous membrane protuberances (Fig. 4c). Maturation of the spermatic cells was not synchronous at the individual level but was evident within each spermatic cyst, encountered atdifferent stages of spermatogenesis, from primary spermatocyte to mature spermatozoa.The early spermatic cysts development had already occurred when the sponges were collectedand the spermatogonia origincould not be observed.

Primary spermatocytespresented numerous cytoplasmic inclusions and a flagellum. The cytoplasm presented several mitochondria $(0.25 \mu \mathrm{m}$ in diameter), which were round shaped with well-defined laminar cristae. The Golgi apparatus was large $(1.7 \mu \mathrm{m}$ long) with an irregular shape and consisted of 3 to 4 cisternae. In addition, several small electron-clear vesicles were visible in this stage (Fig. 4d). The flagella derived from large cytoplasmic outgrowthson one side of the cell. The flagellar basal apparatus was composed of a long basal body $(1.05 \mu \mathrm{m}$ long, $0.2 \mu \mathrm{m}$ in diameter) to which an associated accessory centriole ( $0.71 \mu$ mlong, $0.2 \mu$ min diameter $)$ and alar sheets were found. A rootlet was absent. The basal body was situated near the Golgi apparatus (Fig. 4e-f). The cell shape of the primary spermatocyte was not regular(3.8 $\mu \mathrm{m}$ in diameter)and a rounded nucleus ( $2.5 \mu \mathrm{m}$ in diameter) was observed during this stage. During the prophase I, thenucleus of the primary spermatocyte presented typical synaptonemal complexes (Fig. 4g).

The first meiotic division was not synchronous, primary spermatocytes in -prophase I and secondary spermatocytesoccurred at the same time within each cyst (Fig. 4g-h). Binucleated secondary spermatocytes, deriving from incomplete cytoplasm division at the end of the first meiotic divisionwere recognizable (Fig. 5a). The cytoplasm of the secondary spermatocytes was similar to the previous stage, but the cells were slight smaller. The chromatin formed electron-dense areas in the nucleus ( $1.4 \mu \mathrm{m}$ in diameter). Bi-nucleated cells could be observed after the second meiotic division, indicating the transition from secondary spermatocyte to spermatid stages (Fig. 5a), along with the formation of lipid droplets (Fig. 5b). 
231 (1.2 $\mu \mathrm{m}$ long). In this stage only,a cytoplasmic invagination, forming a pit in the plasma

232 membranearound the basal part of the flagellum was observed. Cytoplasmic bridges were still

233 observed connecting the spermatids (Fig. 5c).

Later, secondary spermatocytes evolved into spermatids, acquiring anelongatedshape ( $3.4 \mu \mathrm{m}$ long, $1.3 \mu \mathrm{m}$ in diameter) and being characterized by chromatin at different stages of condensationas well as a stretched nucleus andthe elongation and in eccentric position $(2.4 \mu \mathrm{m}$ long, $0.9 \mu \mathrm{m}$ in diameter). During this stage, pocket-like cytoplasmic invaginations arose around the basal portion of the flagella (Fig. 5d-e).The spermiogenesiswas accompanied by the full compaction of the nuclear content altogether with the elongation of the nucleus. In addition,residual cytoplasm was shed at the basal sideof the cell or alongside the flagellum reducing the overallvolume of the cell (Fig. 5f-6a).Spermatozoa were elongated (up to $4.2 \mu \mathrm{m}$ long,with a diameter of $1.25 \mu \mathrm{m}$ in basal and $0.83 \mu \mathrm{m}$ in apical portion of the cell),with a long flagellumarising from a cytoplasmic invagination of variable depth(Fig. 6a-b). The anterior part of the nucleus presenteda trapezoid shape in section. Mitochondria with constant spherical shape and diameter (about $0.3 \mu \mathrm{m}$ )occurred at the basal part of spermatozoa (Fig. 6b). No particular orientation of spermatozoa within spermatocystswas noticeable.

Iophon piceus

Iophon piceus is a simultaneous hermaphrodite reproducing throughout the hydrological summer, i.e. late April to early October (Ereskovsky 2000). The spermatogenesis of this species was previously investigated in light and electron microscopy (Efremova et al. 1987) but the samples collected in 2002 are providing more information about the ultrastructure of its spermiogenesis, although only late stage of spermatic cysts were present (Fig. 7a).Spermatids and spermatozoa were enveloped by flattened cellsof the spermatic cyst (Fig. 7a). Spermatids were rounded, measuring ca. $1.4 \mu \mathrm{m}$ in diameter. The residual cytoplasm presented many large electron clear vesicles and some tubules (likely resulting from the degenerating endoplasmic reticulum)specially found in the residual cytoplasmic bridges uniting two or more spermatids (Fig. 7b-c). At this stage, the nucleus was already fully condensed and started to stretch out,as well as the cell, which also gained an elongated shape. The volume of the cell decrease and large electron clear vesicles started to appear in the cytoplasm. (Fig. 7d). A single amorphous crystalline inclusion was then observed in different regions of the cell, but usually close to the nucleus (Fig. 7e-h). The flagellum of the spermatid/spermatozoon was long and free of ornamentation (Fig. 7a-b, e). Even though the insertion of the flagellum was not observed in an invagination of the cell membrane, small microvilli expansions were found at the basis of the flagellum in several sections (Fig. 7e-f, h-i). The accessory centriole was located close to the 
nucleus (Fig. 7d, f) and the basal body was positioned at the posterior end of the cell. Coarse microtubule fibers, supposedly related to the rootlet of the flagellum, spread from the basal body toward the nucleus. The nucleus reached ca. $3 \mu \mathrm{m}$ in length and presented sharp endings in some sections, indicating a truncated tip of the cell (Fig. 7h).

Discussion

We are here describing the morphology of several steps of the spermatogenesis of three species belonging to two different genera of Poecilosclerida. These species inhabit different regions of the globe (from tropics to polar regions), but still present sperm morphology with stark resemblance to each other and to other previous studied poecilosclerids. Sampling was not spread over time for the threepoecilosclerids described here and spermatogenesis was already in progress in all samples examined. Therefore, the cell lineage of the spermatic cellscould not be determined. Nonetheless, based on the position, shape, and sizes of the spermatic cysts of the three investigated species, we hypothesize that they also derive from choanocyte chambers, as showed previously for other poecilosclerids (Pérez-Porro et al. 2012).Thespermatogonia of Tedaniaignis(and also in Iophon piceusEfremova et al. 1987) seemed to lose their flagella during the first divisionand to produce new ones at the later spermatid stage. However, in Iophonproximum, as also occurs in the Homoscleromorpha investigated so far (Gaino et al. 1986; Riesgo et al. 2007b; Ereskovsky 2010) and some freshwater sponges (Paulus 1989), the division ofspermatocytes occurred without the loss of the flagellum. This situation is in contradiction with most Metazoa that have the flagellumappearing only at the late stages of gametogenesis(Reunovand Hodgson 1994). Besides sponges, such situation was only observed in bivalves (Reunovand Hodgson 1994).

In the present study, the spermatozoa of all three species showed an elongate shape (about 5.8x0.7 $\mu \mathrm{m}$ in T. ignis; $4.0 \times 0.9 \mu \mathrm{m}$ in I. piceus; and $4.5 \times 0.8 \mu \mathrm{m}$ in I. proximum). The morphology of their nucleus presented a striking similarity: inT. ignis as in the two Iophon species it was cylindrical with a wavy surface and a trapezium-like anterior end.

BothIophonspeciesshared the presence of a shallow cytoplasmic invagination around the basal part of theirsperm flagellum and an unusually elongated basal body (in I. piceus it was about 1.7 $\mu \mathrm{m}$ and in I. proximum1.1 $\mu \mathrm{m})$. Within the order Poecilosclerida,former investigations in electron microscopy were carried out on Myxilla incrustans(Johnston, 1842), Iophon piceus (Efremova et al. 1987), Lycopodinaoccidentalis(Lambe, 1893) (Riesgo et al. 2007),Crambe crambe(Maldonado and Riesgo 2008), Hemimycalecolumella(Pérez-Porroet al. 2012), Crellomimaimparidens andHymedesmiairregularis(Ereskovsky 2010). The ultrastructure of the spermatozoa of all three speciesinvestigated herewas similar to that formerly observed for the 
sperm of I. piceus (Efremova et al. 1987) and of L. occidentalis(Riesgo et al. 2007). In addition, the presence of a shallow invagination in the flagellum insertion of $I$. proximumand I. piceus is similar to that observed in the sperm cells of H. columella (Pérez-Porroet al. 2012). Nevertheless, the very sophisticated spermatozoon observed in C. crambe (V-shaped) (Riesgo and Maldonado 2009) was not observed in any of the three investigated species and is still a peculiarity of this Mediterranean species.Crambecrambeis, apparently, in a sister-group of all other poecilosclerids investigated so far (Hestetun et al. 2016). It could be, therefore, that this sophisticated characteristic of the sperm of C. crambe is restricted to the lineage of the Crambeidae, rather than widely spread in Poecilosclerida as a whole. We expect that new investigations in other species of Crambe and ofMonanchora, for example, are likely to answer this question.

Elongated and V-shaped spermatozoa with elongated nucleus are considered as 'modified' and are widely regarded as a derived character in Metazoa (Reunov 2005). The cooccurrence of 'primitive' and 'modified' spermatozoa is a situation established in Porifera prior to the emergence of higher metazoans. The occurrence of 'modified' spermatozoa among Porifera sharing many ultrastructural traits with those of higher metazoans could be explained by multiple cases of convergent evolution (Riesgo and Maldonado 2009).The same explanation might also be useful for the acrosome. Most spermatozoa of Porifera described until de end of the 1990's lacked an acrosome (Boury-Esnault and Jamieson 1999) and it was commonly admitted that they allwere of the 'primitive' type and were more basic than the primitive sperm of the majority of the other groups of metazoans. However, acrosomes were revealed in spermatozoa of Homoscleromorpha (Ereskovsky 2010), of two Calcarea species (Nakamura et al. 1997; Lanna and Klautau 2010) and also in several Demospongiae, especially Poecilosclerida (Riesgo et al. 2007; Riesgo and Maldonado 2009; Ereskovsky 2010).The spermatozoa of T.ignis presented small vesicles on top of the nucleus, that are likely preacrosomal vesicles, as in other Poecilosclerida(L. occidentalis, C. crambe, and Crellomimaimparidens(Rezvoi, 1925))(Riesgo et al. 2007; Riesgo and Maldonado 2009; Ereskovsky 2010). In contrast, in the spermatozoa of I. piceus and I. proximumthese electron dense granules were absent, as in M. incrustans (Efremova et al. 1987). Historically, the presence of acrosome in Porifera brought the following question: is the acrosome a primitive organelle that disappeared during evolution in most of the orders, or a new organelle secondarily evolved in a few species? (Baccetti 1986). In the past, thesperm ultrastructure in sponges supported the hypothesis presented by Afzelius(1972) that primitive spermatozoa may have arisen twice, once in Porifera and another inall other metazoans. The sperm in Porifera seems to have arisen primarily from choanocytes and has probably evolved independently of sperm in Cnidaria and other groups(Franzén1996). However, it is now being suggested that the 
spermatozoon is homologous in all Metazoa and that the absence of acrosome in most sponges could be a derived condition (Boury-Esnaultand Jamieson 1999; Riesgo and Maldonado 2009). Apparently, the general shape of the sperm might be related more to the fecundation physiology of the animal, than being constrained by the phylogeny of the group.Although some similaritiescould be observed amongst the three poecilosclerids investigated here, especially in the elongated shape of the sperm cell, the morphology of the spermatozoa of these species still presentdistinctive characteristics from each other.Expanding the investigations to other poeciloscleridsis mandatory if we are to understand whether the diversity of sperm cell morphology is related to the phylogeny of the group or an adaptation to the fertilization process. Nonetheless, till these new studies investigating a large variety of species in different lineages of the group is carried out, we suggest that the "modified" sperm (elongated with a basal flagellum) is the ancestral state in the lineage. Further modifications in the morphology of the sperm, as the V-shaped ones of C. crambe (Riesgo and Maldonado 2009), are novelties within Poecilosclerida. We conclude that the current data about spermatozoa ultrastructure in Porifera as a whole (and in Poecilosclerida, particularly) is not sufficient to be used for taxonomy or phylogeny as already proposed in other groups of metazoans, e.g.annelids, insects, birds (Tudge 2009). However, it indicates that the fertilization (which is largely unknown in Demospongiae, Ereskovsky 2010) of these different species could be carried out in an apparently similar pattern.

\section{Acknowledgements}

We would like to thank the staff at the Serviços de Microscopia Eletrônica - CPqGM-Fiocruz for help with the preparation of the samples of T. ignis. The present work is part of the $\mathrm{PhD}$ thesis of VV presented at the PPG em Diversidade Animal of the Federal University of Bahia. Brazilian sample collections were carried out under the license of ICMBIO (\#9321-1). EL and VV thank the Foundation for Researcher Support of the State of Bahia (FAPESB - grant $n$. JCB0014/2016) and the National Council for Sientific and Technological Development (CNPq - grant n. 477227/2013-9) for the financial assistance. VV received a PhD scholarship from CAPES.PhW and AE are indebted to Professors I. Eeckhaut and P. Flammang, Laboratoire de Biologie Marine, Université de Mons for their cordial reception in the TEM facilities under their care.Professors E. Pays and D. Pérez-Morga are also thanked for welcoming us in the Centre for Microscopy and Molecular Imaging of the Université Libre de Bruxelles.J. Cillis (RBINS) gave us technical support of with the SEM. We are grateful to G.Försterra and V. Häussermann (Huinay Scientific Field Station, Chile) and the Huinay Foundation without whom collecting Iophonproximum would not have been possible. Both are further thanked, as well as 

«Belomorskaia» of St. Petersburg State University for the possibilities to collect Iophonpiceum. The Belgian Federal Science Policy Office funded the work of AE at the RBINS (S \& T Grant for collaboration with Oriental and Central Europe) as well as fieldwork of PhW in Chile (CALMARS I-contract EV/03/04B).ThisispublicationNumber 62 from the Huinay Scientific Field Station.

References

Afzelius BA (1972) Sperm morphology and fertilization biology In: Beatty RA, Gluecksohn-

Waelsch S (eds) The Genetics of the Spermatozoon, pp. 131-143

Baccetti B (1986) Evolutionary trends in sperm structure. Comp BiochemPhysiol85A: 29-36. https://doi.org/10.1016/0300-9629(86)90457-3

Bergquist P (1978) Sponges, Hutchinson, California

Boury-Esnault N, Jamieson BGM (1999) 1. Porifera. In: Adiyodi KG, Adiyodi RG (eds)

Reproductive Biology of Invertebrates. New Delhi, Oxford \& IBH Publishing, pp 1-41

Efremova SM, Ereskovsky AV, Tokina DB (1987) Gametogenesis in sponges of the family (Demospongia, Poecilosclerida) Ontogenez3: 263-268.

Ereskovsky AV (2010) The comparative embryology of sponges. Dordrecht Springer

Franzén Å (1956) On spermiogenesis, morphology of spermatozoon and biology of fertilization among invertebrates.ZoolBidrUpp3:355-482

Franzén A (1996) Ultrastructure of spermatozoa and spermiogenesis in the hydrozoan Cordylophoracaspia with comments on structure and evolution of the sperm in the Cnidaria and the Porifera. InvertebrReprodDev 29:19-26. https://doi.org/10.1080/07924259.1996.9672491

Gaino E, Burlando B, Buffa P, Sarà M (1986) Ultrastructural study of spermatogenesis in Oscarella lobularis (Porifera, Demospongiae). Int J Invert Rep Dev 10: 297-305. http://dx.doi.org/10.1080/01688170.1986.10510253 (2016) The systematics of carnivorous sponges. Mol PhylEvol 94:327-345. 
409 L'Hernault SW (2006) Spermatogenesis. WormBook, 1-14.

410 https://doi.org/10.1895/wormbook.1.85.1

411 Lanna E, Klautau M (2010) Oogenesis and spermatogenesis in Paraleucilla magna (Porifera, 412 Calcarea). Zoomorphology, 129:249-261. https://doi.org/10.1007/s00435-010-0117-5

413 Lanna E, Cajado B, Santos da Silva C, da Hora J, Porto U, Vasconcellos V (2018) Is the Orton's 414 rule still valid? Tropical sponge fecundity, rather than periodicity, is modulated by temperature 415 and other proximal cues. Hydrobiologia. https://doi.org/10.1007/s10750-018-3562-7

416 Maldonado M, Riesgo A (2008) Reproduction in the phylum Porifera: a synoptic overview.

417 Treballs de la SCB, 59:29-49. https://doi.org/10.2436/20.1501.02.56

418 Meroz E, Ilan M (1995) Life history characteristics of a coral reef sponge. Mar Biol 124:443419 451. https://doi.org/10.1007/BF00363918

420 Nakamura Y, Okada K, Watanabe Y (1998) The ultrastructure of spermatozoa and its ultrastructural 421 change in the choanocyte of Sycon calcaravisHozawa. In: Watanabe Y, Fusetani N (eds). Sponge 422 Sciences. Multidisciplinary perspectives. Springer-Verlag, Tokyo

423 Paulus, W., 1989. Ultrastructural investigation of spermatogenesis in Spongilla lacustris and 424 Ephydatia fluviatilis (Porifera, Spongillidae). Zoomorphology 109(3):123-130.

425

426

427

428

Pérez-Porro AR, González J, Uriz MJ (2012) Reproductive traits explain contrasting ecological features in sponges: The sympatric poecilosclerids Hemimycale columella and Crella elegans as examples. Hydrobiologia, 687:315-330. https://doi.org/10.1007/s10750-011-0919-6

Pitnick S, Hosken DJ, Birkhead TR (2009) Sperm morphological diversity In: Birkhead TR, Hosken DJ, Pitnick S (ed) Sperm Biology: An evolutionary perspective, Elsevier, pp 60-149

Redmond NE, Morrow CC, Thacker RW (2013) Phylogeny and systematics of Demospongiae in light of new small-subunit ribosomal DNA (18S) sequences. Integr Comp Biol 53:388415. https://doi.org/10.1093/icb/ict078

Reiswig HM (1983) 1. Porifera In:Adiyodi KG \&Adiyodi RG (eds) Reproductive Biology of Invertebrates. New Delhi, Oxford \& IBH Publishing, pp 1-21

Reunov AA, Hodgson AN (1994) Ultrastructure of the spermatozoa of five species of south african bivalves (Mollusca), and an examination of early spermatogenesis. J Morphol 219: 275283. https://doi.org/10.1002/jmor.1052190307

Reunov AA (2005) Problem of terminology in characteristics of spermatozoa of Metazoa. Russ J DevBiol36:335-351. https://doi.org/10.1007/s11174-005-0050-6

Reynolds, E.S. (1963) The use of lead citrate at high $\mathrm{pH}$ as an electron-opaque stain in electron microscopy. J Cell Biol 17:208-212. http://dx.doi.org/10.1083/jcb.17.1.208. 
Riesgo A, Taylor C, Leys SP (2007)Reproduction in a carnivorous sponge: the significance of the absence of an aquiferous system to the sponge body plan. EvolDev 9:618-

Riesgo A, Maldonado M, Durfort M (2007b) Dynamics of gametogenesis, embryogenesis, and larval release in a Mediterranean homosclerophorid demosponge. Mar Freshwater Res58:398417.https// doi.org/10.1071/MF06052

Simpson TL (1984) The cell biology of sponge. Springe-Verlag, New York, pp 662. DOI:

Spurr AR (1969) A low-viscosity epoxy resin embedding medium for electron microscopy. J Pisera AB, Manconi R, Schönberg C, Klautau M, Picton B, Kelly M, Vacelet J,Dohrmann M, Díaz MC, Cárdenas P, Carballo JL, Ríos P, Downey R. (2018) World Porifera database. http://www.marinespecies.org/porifera. Accessed 28 May 2018

Vargas S, Erpenbeck D, Göcke C, Hall KA, Hooper JNA, Janussen D, Wörheide G (2015)Molecular phylogeny of Abyssocladia (Cladorhizidae: Poecilosclerida) and Phelloderma (Phellodermidae: Poecilosclerida) suggests a diversification of chelae microscleres in cladorhizid sponges. Zool Scr.doi:10.1111/j.1463-6409.2012.00560.x

White-Cooper H, Dogget K, Ellis RE (2009) The evolution of spermatogenesis In: Birkhead

Figure captions

472 Figure 1. In situ photographs of the investigated poecilosclerids: (a) Tedania ignisfrom Salvador 473 de Bahia, Brazil. (b) Iophon proximumfrom Comau Fjord, Chile. (c) Iophon piceus from White Sea, Russia.

476 Figure 2. Tedania ignis: Spermatic cysts and spermatogonia. (a) Choanosome (ch)with different 477 spermatic cysts (sc) enveloped by a thin layer of follicle cells (cryofracture seen in SEM). (b)

478 Spermatic cyst (sc) with spermatic cells developing in synchrony(LM). (c) Spermatids (spd),

479 flagella (fl) and a large somatic cell (so) within a late stage spermatic cyst(TEM). (d)

480 Spermatogoniumand its large nucleus (n) with compacting chromatin and clear cytoplasm (cy) 
481 (TEM). (e)Mitochondria (mi) and a Golgi apparatus (ga) in the cytoplasm of a spermatogonium.

482 Arrows indicate follicle cells.

Figure 3. Tedania ignis: Spermatocytes and spermatids. (a) Spermatogonia (sp) and primary spermatocytes (sc1) in a spermatic cyst(mes - mesohyl). (b) Primary spermatocyte with a large nucleus ( $\mathrm{n}$ ) in prophase I (arrows indicate synaptonemal complex) clear cytoplasm (cy) and Golgi apparatus (ga). (c) Spermatic cyst withsecondary spermatocytes (sp2), spermatids (spd) and spermatozoa (spz). (d) Secondary spermatocytes connected through cytoplasmic bridges (cb) (mi - mitochondria; $\mathrm{n}$ - nucleus). (e) Secondary spermatocyte in a late stage of transition towards spermatid, with compacting heterochromatin (hc) in the nucleus (n) ( $\mathrm{fl}$ - flagellum; mi - mitochondria). (f) Mid stage spermatid with cytoplasm containing many clear vesicles (cv). An elongated nucleus (n) is above the axoneme (ax). (g) Spermatid in a late stage, with stretched out nucleus (n) in the apical portion of the elongated cell.The base of the flagellum (fl) appears in the cytoplasm. (h) Basal portion of the spermatid (neck) showing the flagellum (fl) emerging from the cytoplasm, several mitochondria (mi)and clear vesicles (cv). (i) Tip of a late stage spermatid showing the pre-acrosomal vesicles (arrow) ( $n$ - nucleus).

Figure 4. Iophon proximum: Spermatic cysts, spermatogonia, and primary spermatocytes. (a) Spermatic cysts (sc) at different maturation stages in the choanosome. (b) Detail of a spermatic cyst (sc),(fc - follicle cells; mes - mesohyl). (c) Detail of a follicle cell with membranous protuberances (mb). (d) Spermatogonia with a large nucleus (n) andGolgi apparatus (ga). (e) Primary spermatocyte showing basal body and accesory centriole (ac) of the flagellum (fl).(f) Detail of the long basal body (bb) close to the Golgi apparatus (ga) and the accessory centriole (ac). (g) Primary spermatocyte with nucleus (n) in prophase I (arrows indicate synaptonemal complexes). (h) Secondary spermatocyte with a large nucleus (n) and compacting chromatin. Mitochondria (mi) are abundant in all stages.

507

Figure 5. Iophon proximum: Secondary spermatocytes and spermatids of I. proximum. (a) Secondary spermatocyte (spc2) soon after nuclear division. (b) Detail of a secondary spermatocyte with a large nucleus. (c) Two secondary spermatocytes united by cytoplasmic bridges (cb). (d) Spermatids with compacted and elongated nucleus and cytoplasm being shed. Several mitochondria (mi) are located in the putative neck of the sperm cell and the flagellum (fl) is emerging from a deep pit (arrows) in the cytoplasm. (e) Detail of the neck of the spermatids with the flagellum insertion in the invagination of the cell (arrows). (f) Late

515 spermatid with stretched nucleus and residual cytoplasm (rc) being shed alongside the cell.(cy 516 cytoplasm; mi - mitochondria; $\mathrm{n}$ - nucleus; spc1 - primary spermatocyte). 
518 Figure 6. Iophon proximum: Spermatozoon. (a) Spermatozoon (spz) with long flagellum seen in

519 SEM. (b) TEM view of the spermatozoon showing compacted nucleus (n) with a trapezoid

520 apical shape (fl - flagellum; mi - mitochondria).

521

522 Figure 7.Iophon piceus: Spermatids. (a) Overview of a spermatic cyst (sc) with spermatids

523 (spd)(mes- mesohyl; fc - follicle cells). (b) Spermatids still connected by cytoplasmic bridges

524 (cb). (c) detail of the cytoplasmic bridge seen in b, with the presence of several microtubules.

525 (d) Spermatids containing important clear vesicles (cv). The centriole (ce) is inserted alongside

526 the compacted nucleus. (e) Late spermatid with globular shape. A crystaline amorphous

527 inclusion (ai) is located next to the compacted nucleus. The flagellum is inserted in the neck of

528 the cell attached to the basal body (bb). A fibrous rootlet (r) is connected to the nucleus. (f)

529 Detail of the flagellum (fl) insertion showing the basal body (bb) and the accessory centriole

530 (ac). (g) Amorphous inclusions are located in different regions of the cytoplasm. The tip of the

531 nucleus bears a trapezoid shape (arrow). (h) Elongated spermatid with long nucleus and

532 trapezoid apical shape (arrow). (i) Detail of the basal body (bb) and a microvilosity at the neck

533 of the spermatid. (ai - amorphous inclusion; fl - flagellum; mv - microvilosity; $\mathrm{n}$ - nucleus). 

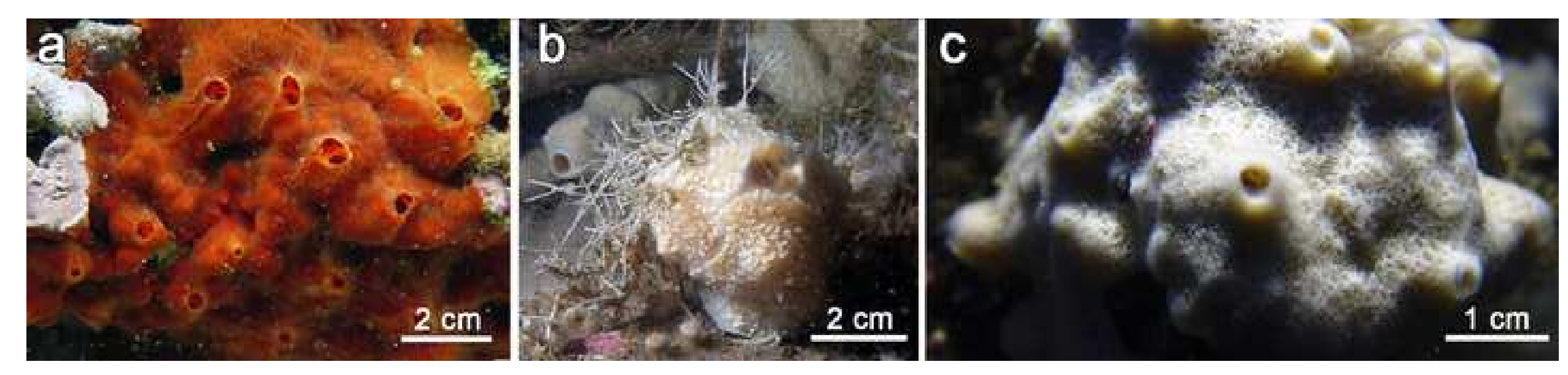


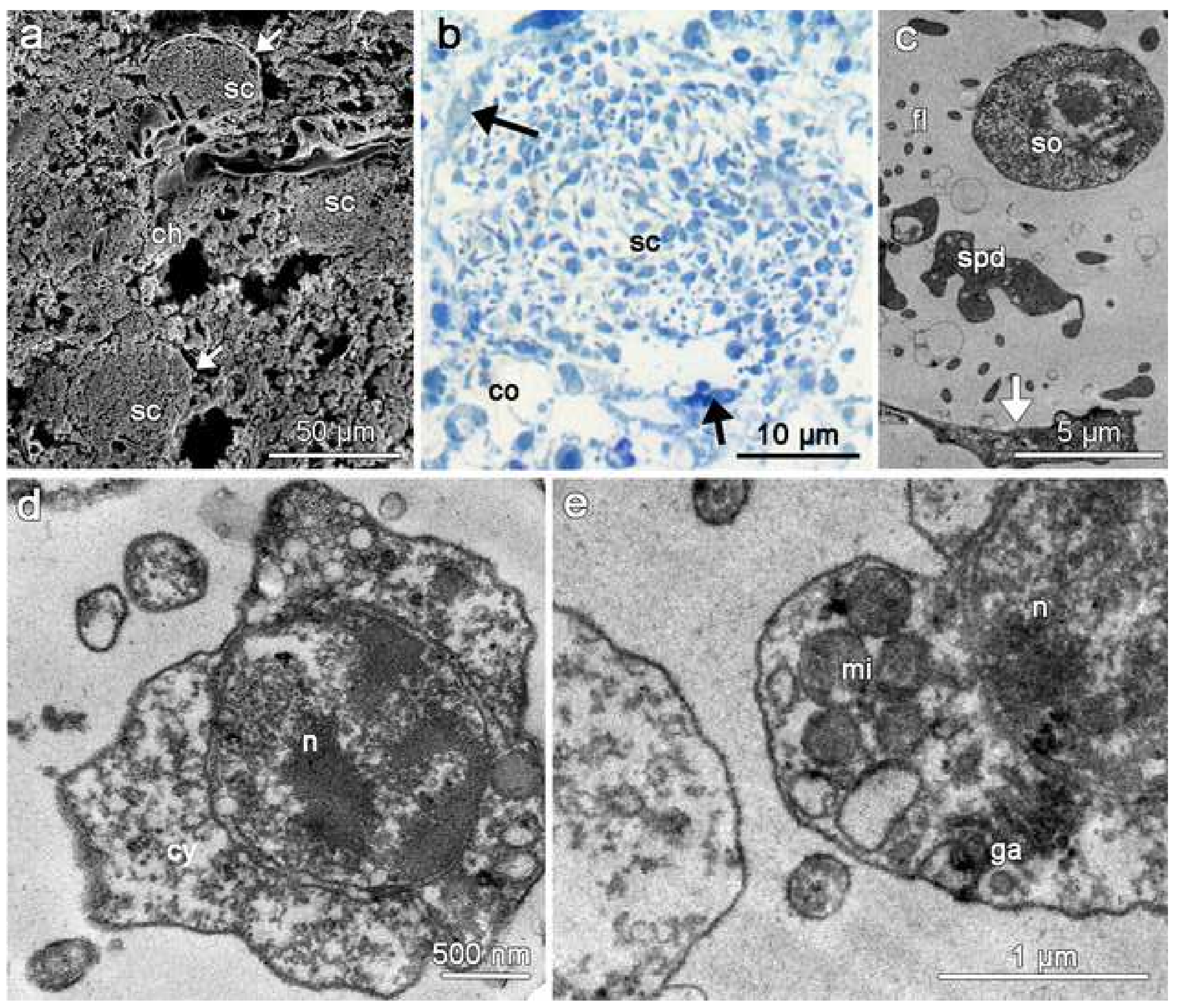



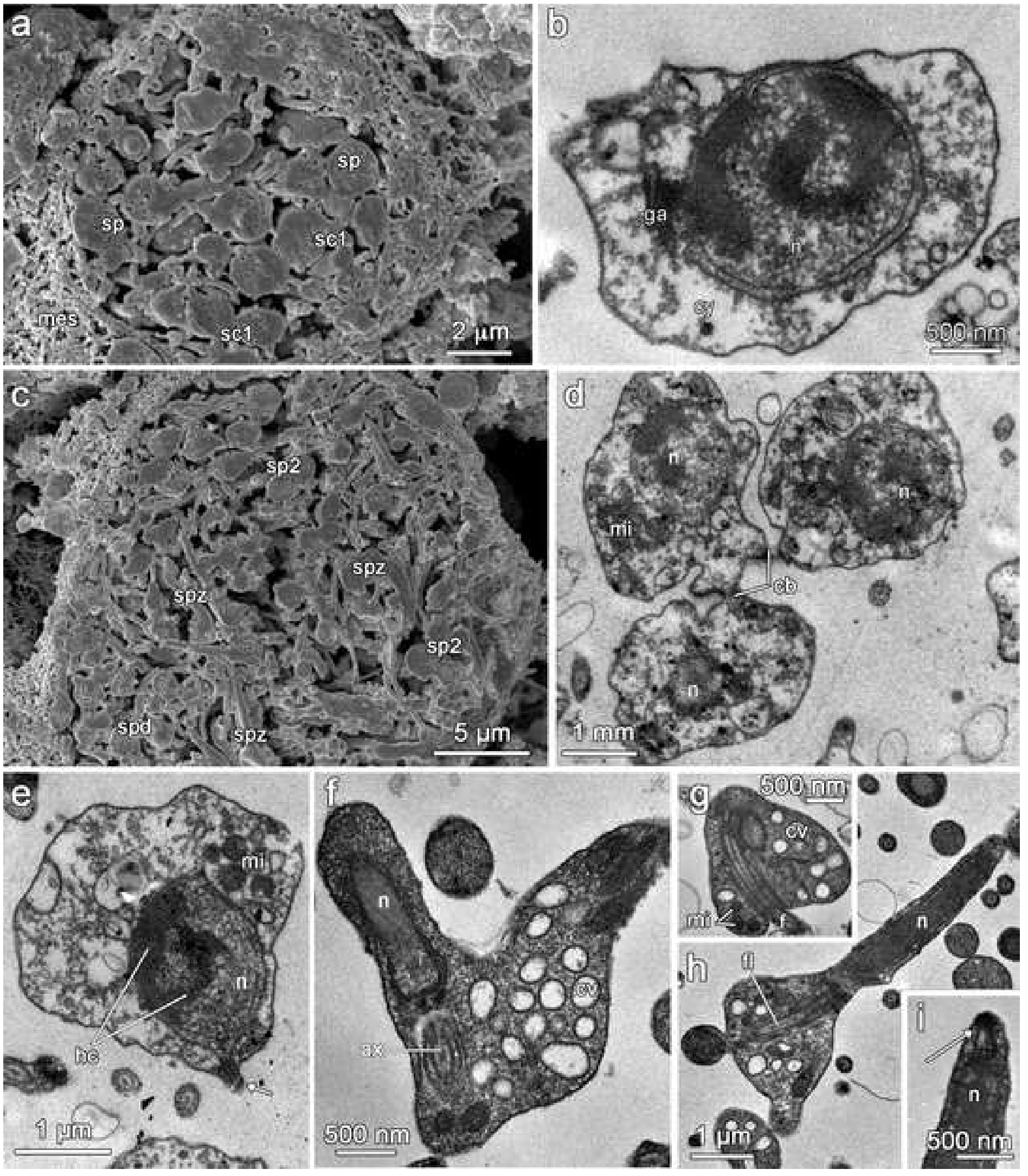

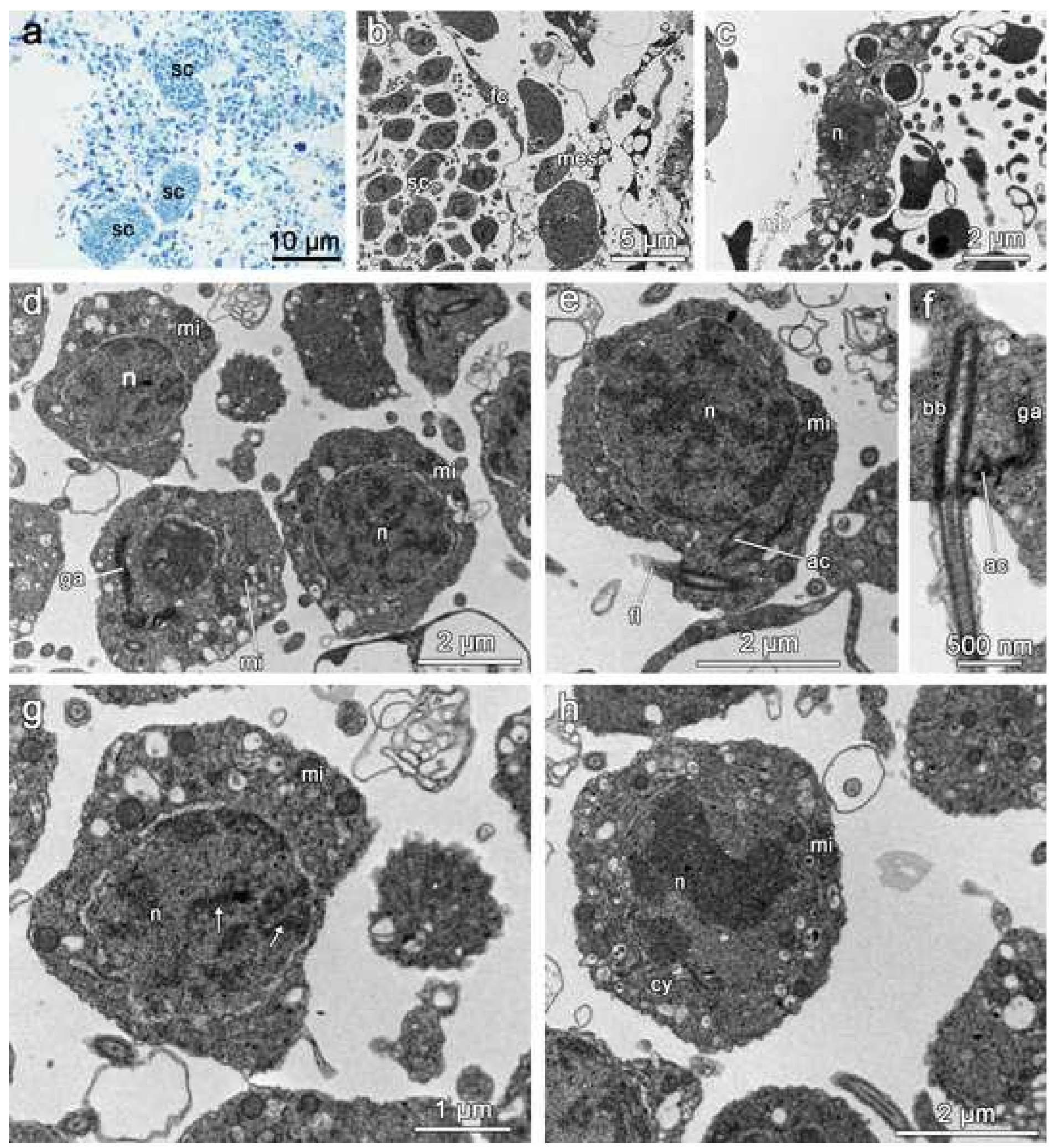
(a)
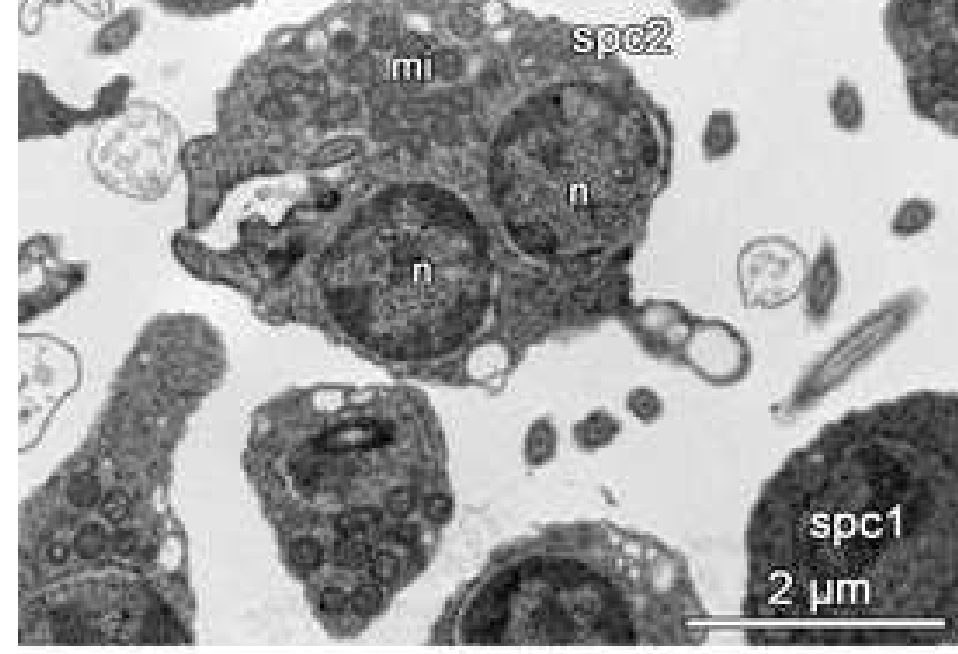

G
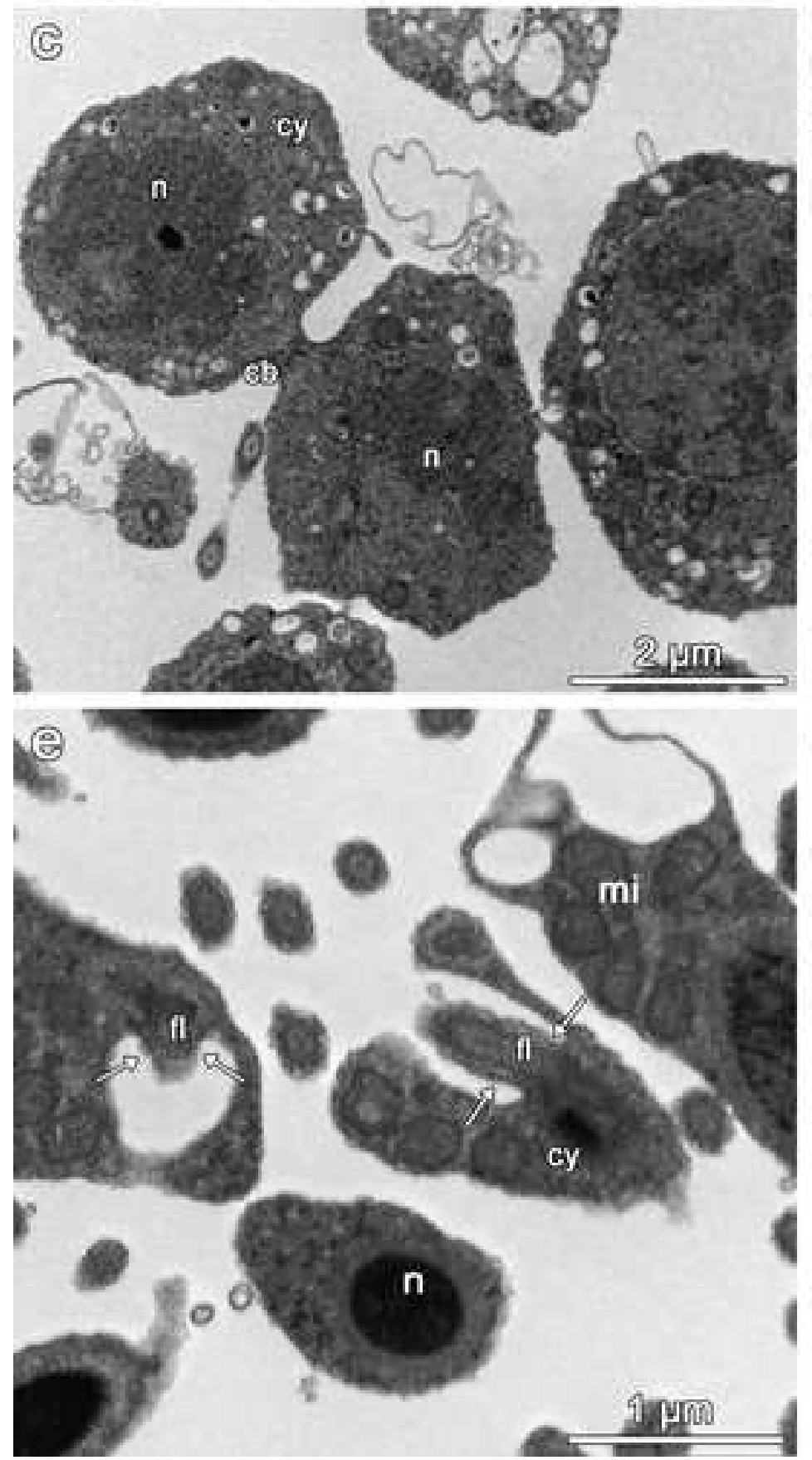
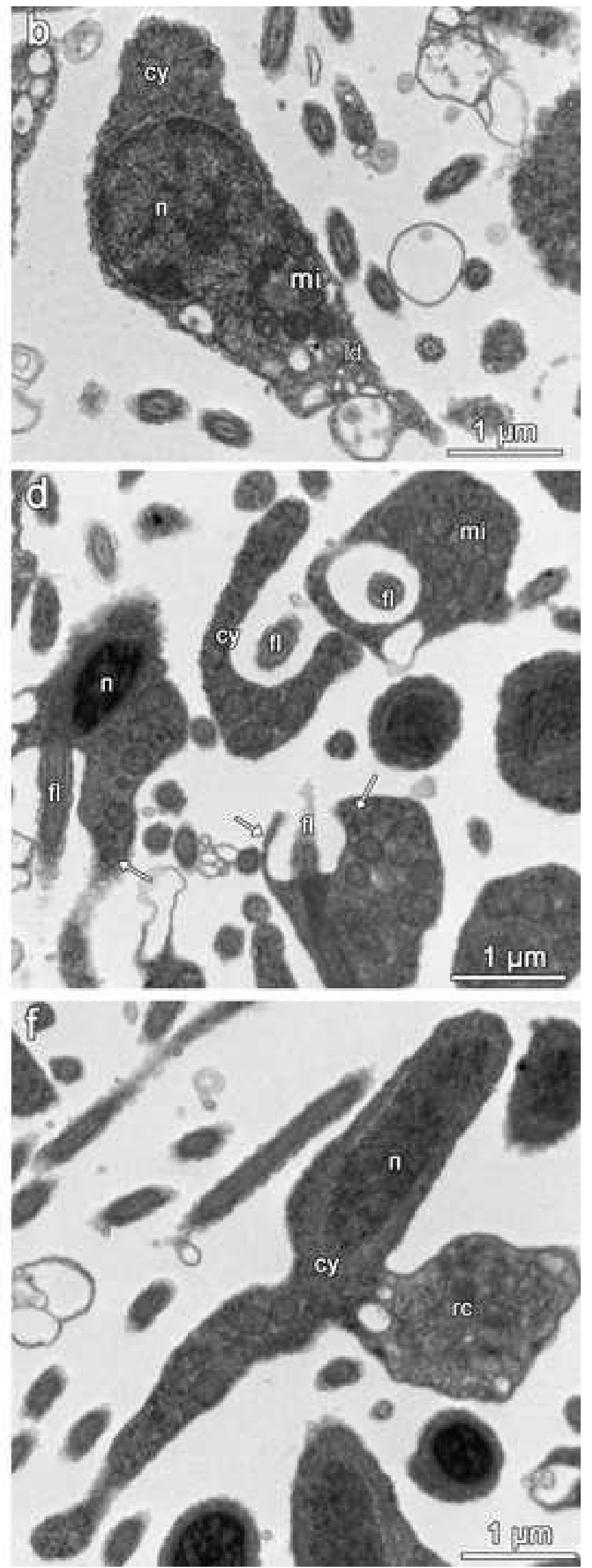

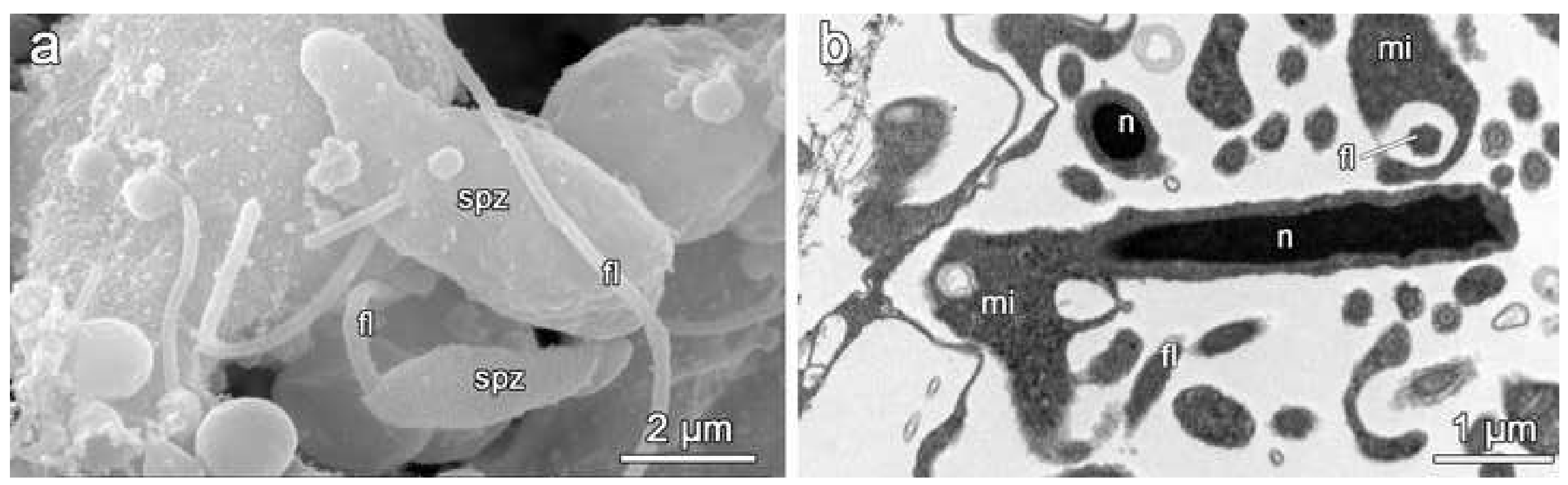


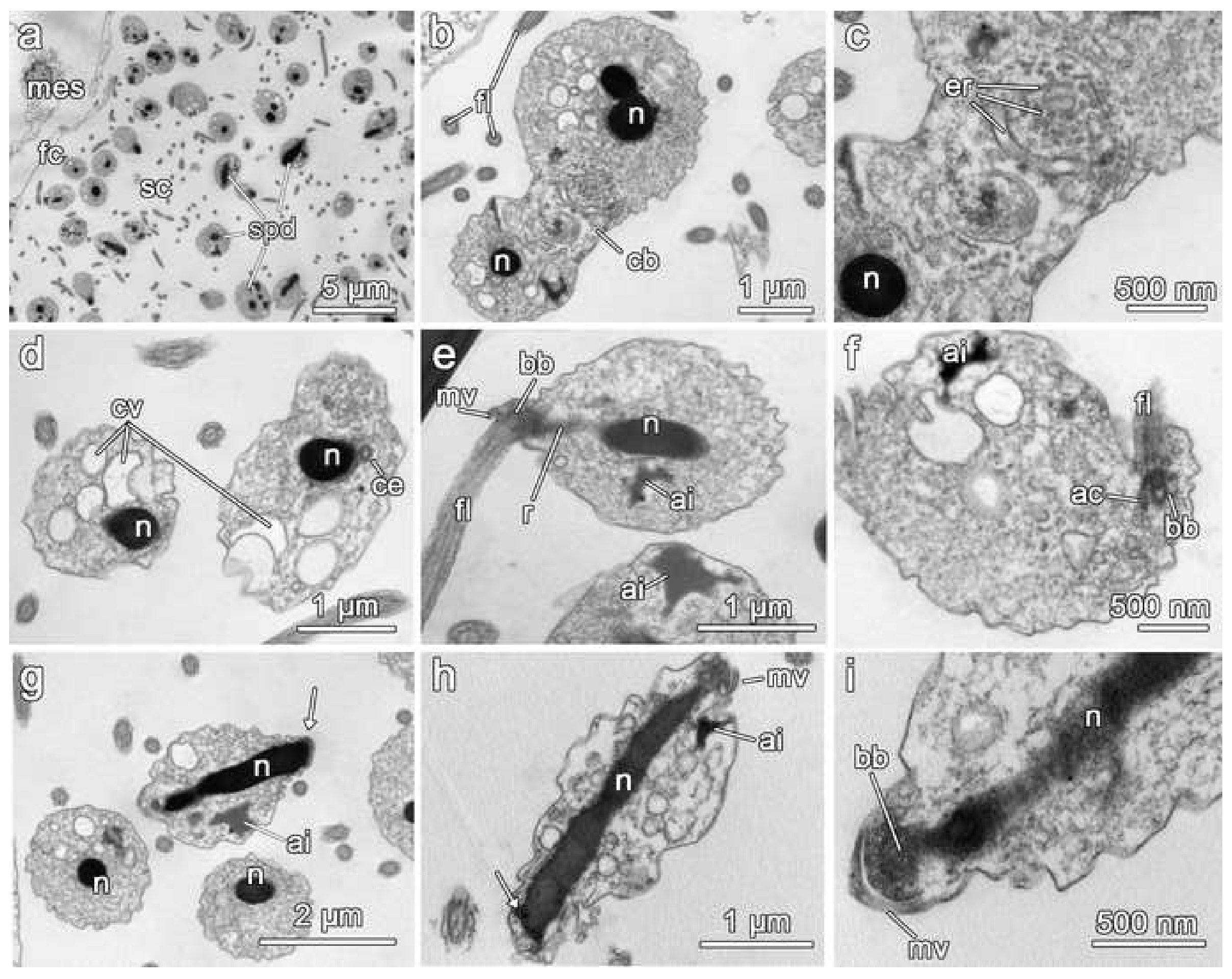

